\title{
The Dalton Minimum and John Dalton's Auroral Observations
}

\author{
Sam M. Silverman ${ }^{1, *}$, and Hisashi Hayakawa ${ }^{2,3,4, *}$ \\ 18 Ingleside Road, Lexington, 02420, MA, USA \\ 2 Institute for Space-Earth Environmental Research, Nagoya University, 4648601 Nagoya, Japan \\ ${ }^{3}$ Institute for Advanced Researches, Nagoya University, 4648601 Nagoya, Japan \\ ${ }^{4}$ UK Solar System Data Centre, Space Physics and Operations Division, RAL Space, Science and Technology Facilities Council, \\ Rutherford Appleton Laboratory, Harwell Oxford, Didcot, OX11 0QX Oxfordshire, UK
}

Received 7 December 2020 / Accepted 26 December 2020

\begin{abstract}
In addition to the regular Schwabe cycles of approximately $11 \mathrm{y}$, "prolonged solar activity minima" have been identified through the direct observation of sunspots and aurorae, as well as proxy data of cosmogenic isotopes. Some of these prolonged minima have been regarded as grand solar minima, which are arguably associated with the special state of the solar dynamo and have attracted significant scientific interest. In this paper, we review how these prolonged solar activity minima have been identified. In particular, we focus on the Dalton Minimum, which is named after John Dalton. We review Dalton's scientific achievements, particularly in geophysics. Special emphasis is placed on his lifelong observations of auroral displays over approximately five decades in Great Britain. Dalton's observations for the auroral frequency allowed him to notice the scarcity of auroral displays in the early 19th century. We analyze temporal variations in the annual frequency of such displays from a modern perspective. The contemporary geomagnetic positions of Dalton's observational site make his dataset extremely valuable because his site is located in the sub-auroral zone and is relatively sensitive to minor enhancements in solar eruptions and solar wind streams. His data indicate clear solar cycles in the early 19th century and their significant depression from 1798 to 1824 . Additionally, his data reveal a significant spike in auroral frequency in 1797, which chronologically coincides with the "lost cycle" that is arguably located at the late Solar Cycle 4. Therefore, John Dalton's achievements can still benefit modern science and help us improve our understanding of the Dalton Minimum.
\end{abstract}

Keywords: aurora / Dalton minimum / John Dalton / scientific history / solar cycles / the lost cycle

\section{Introduction}

Mid-latitude aurorae visually manifest solar eruptions and high-speed solar wind streams interacting with terrestrial fmagnetic fields (Gonzalez et al., 1994; Daglis et al., 1999). Their visibility has been intermittently recorded for millennia in various historical documents (Silverman, 1998, 2006; Stephenson et al., 2004; Vaquero \& Vázquez, 2009). These records provide valuable scientific insights into long-term solar variability and solar eruptions prior to telescopic observations (Silverman, 1992, 2006; Willis and Stephenson, 2001; Willis \& Davis, 2015; Lockwood \& Barnard, 2015; Ebihara et al., 2017; Hayakawa et al., 2017a, 2017b, 2019a, 2019b; Hattori et al., 2019; Stephenson et al., 2019), particularly when considered in combination with cosmogenic isotope data (Usoskin et al., 2007; Inceoglu et al., 2015; Usoskin, 2017; Barnard et al., 2018; Miyake et al., 2019).

\footnotetext{
*Corresponding authors: silvermansamlll@gmail.com; hisashi@nagoya-u.jp
}

Since the seminal work of de Mairan (1733) on auroral frequency, it has been recognized that there are intervals with considerably diminished auroral activity. In particular, Eddy (1976) has marshaled the evidence for a prolonged solar activity minimum called the Maunder Minimum from 1645 to 1715. This grand minimum has served as a benchmark for long-term solar variability with a significant reduction in sunspot occurrence (Usoskin et al., 2015; Vaquero et al., 2015; MuñozJaramillo \& Vaquero, 2019) and apparent loss of solar coronal streamers (Riley et al., 2015; Hayakawa et al., 2020c). A significant decrease in auroral visibility in the European sector was significant given the high magnetic latitude of this sector during this time period, which would generally cause one to expect more frequent auroral sightings (e.g., Usoskin et al., 2015; Hayakawa et al., 2020d).

Additional evidence has been found in New England, where an aurora was first observed in December of 1719. Lovering (1867, p. 102) noted that it was unlikely that any conspicuous aurora prior to that date would not have been remarked upon 
because "The people of New England were too much inclined to exaggerate every unusual phenomenon in the heavens to have overlooked or been silent in regard to a spectacle so strange as the aurora, had they had the opportunity of beholding one." In fact, the New England appearance in 1719 filled the country with alarm and many believed that it was a sign of the second coming of Jesus Christ, and that the final judgment was about to commence. In England, Halley (1716), who observed the aurora of 1716 at the age of $60 \mathrm{y}$, noted that an aurora had not appeared in that part of England since he was born and that he had expected to die without seeing one. He cited a number of observations regarding aurorae appearing between 1560 and 1581 , indicating that it was fairly common during that period (see also Usoskin et al., 2015). Similarly, Celsius in Sweden stated that aurorae had been rarely seen there before 1716 , but there were 316 observations between 1716 and 1732. de Mairan (1733) noted a comment by Anderson, writing about Iceland, that the older inhabitants were astonished at the frequent appearance of aurorae compared to former times. In 1737, Zanotti (1738) commented that aurorae, formerly rare and almost unknown in Italy, had become very frequent. Halley, Leibnitz, Kirch, Fontenelle, and Maraldi all described the aurorae in the first half of the 18th century as uncommon sights. Cassini, a careful observer, did not note the appearance of any aurorae in the latter half of the 17 th century. The great weight of contemporaneous evidence throughout Europe, New England, and what were considered the more northerly latitudes of southern Sweden and Iceland indicates considerably diminished auroral activity during the latter half of the 17th century compared to the first half of the 18th century (Silverman, 1992).

A similar prolonged solar activity minimum from the late 1790 s to 1827 has been observed in contemporary sunspot records (Clette et al., 2014; Svalgaard \& Schatten, 2016; Muñoz-Jaramillo \& Vaquero, 2019; Hayakawa et al., 2020a). This interval also has considerable contemporaneous evidence in the form of auroral data to support this observation. As summarized by Silverman (1992), auroral displays were much less frequently recorded in Great Britain and Ireland, especially during the period from 1810 to 1826 , and were also missed from 1807 to 1827 in Paris (France), 1789 to 1801 in Karlsruhe (Germany), and 1797 to 1814 in New England. In fact, this trend has been globally confirmed by the auroral records in the European sector (Krivsky \& Pejml, 1988; Nevanlinna, 1995; Schröder et al., 2004; Lockwood \& Barnard, 2015) and Canadian observatories (Broughton, 2002), as summarizedf by Vázquez et al. (2016). However, caveats must be considered here because these catalogs contain compiled auroral reports from multiple datasets with different observational practices, resulting in poor homogeneity. Therefore, observational records from individual observers should be considered to understand temporal variability in long-term auroral frequency. Such observers include Thomas Hughes at Stroud (UK) from 1771 to 1813 (Harrison, 2005), Francisco Salvá at Barcelona (Spain) from 1780 to 1825 (Vaquero et al., 2010), and Giuseppe Tolado at Padua (Italy) from 1766 to 1797 (Domínguez-Castro et al., 2016).

In this context, we examine the auroral observations of John Dalton, after whom the Dalton Minimum was named and whose significant achievements have been emphasized in previous publications (e.g., Silverman, 1992; Lockwood \& Barnard, 2015). Because he conducted auroral observations at Kendal up to 1793 and at Manchester after that point (Henry, 1854), his observational records are more sensitive to auroral displays connected to recent geomagnetic storms. Because magnetic storms tend to be less intense under reduced solar activity (e.g., Usoskin et al., 2015; Vázquez et al., 2016), Dalton had a greater opportunity to observe auroral displays over time and has provided us with significantly more data regarding the temporal variability of auroral frequency during the Dalton Minimum compared to the data in other catalogs derived from southern European records (e.g., Vaquero et al., 2010). Additionally, his observations span almost five decades (17861834) and chronologically cover a period longer than the entire interval of the Dalton Minimum (1797-1827; see Usoskin, 2017). This chronological coverage makes Dalton's records particularly valuable because sunspot observations during the Dalton Minimum are relatively scarce based on gaps between long-term sunspot observers (e.g., Svalgaard \& Schatten, 2016; Vázquez et al., 2016; Hayakawa et al., 2020a). Additionally, Dalton's records accommodate the controversial reconstruction of contemporary solar activity (e.g., Clette \& Lefèvre, 2016; Svalgaard \& Schatten, 2016; Usoskin et al., 2016; Chatzistergos et al., 2017) and highlight the possibility of a lost solar cycle around the onset of the Dalton Minimum (e.g., Usoskin et al., 2009). In this article, we clarify how the Dalton Minimum came to be named after Dalton, highlight Dalton's personal profile and geophysical achievements, and compile and analyze his auroral observations.

An extended review of the auroral background was presented by Siscoe (1980). He expanded auroral databases by incorporating several European and Asian databases, and considered the impact of solar variables, migration of earth's magnetic pole, and variations in the magnetic dipole. Subsequent work has been detailed above.

\section{Naming of the Grand Minima and the Dalton Minimum}

In addition to the regular Schwabe cycles of approximately $11 \mathrm{y}$, evidence of "prolonged solar activity minima" has been identified in direct sunspot observations, particularly in the period from 1645 to 1715 (e.g., Spörer, 1889; Maunder, 1922; see Table 1 and Fig. 1). Eddy (1976) named this minimum as the Maunder Minimum after the British astronomer who wrote a seminal paper on the minimum from the middle of the 17 th century to the early years of the 18th century (e.g., Maunder, 1922). The Maunder Minimum has been independently confirmed to represent enhancements of ${ }^{14} \mathrm{C}$ and ${ }^{10} \mathrm{Be}$ as a result of a weakened solar magnetic field and increased inputs of cosmic rays (Eddy, 1976; see also Usoskin et al., 2015).

Following the onset of sunspot observations in 1610 (e.g., Clette et al., 2014; Arlt \& Vaquero, 2020), similar prolonged solar minima have been identified in cosmogenic isotope data based on long-term enhancements of ${ }^{14} \mathrm{C}$ and ${ }^{10} \mathrm{Be}$ (e.g., Usoskin, 2017; see Table 1). Major prolonged solar minima over the past millennium gained notoriety in solar physics following a series of studies in the 1970s and 1980s. One of the early minima from 1390 to 1550 was named the Spörer Minimum by Eddy (1976, p. 1196) after Gustav Spörer, who extended studies on the Schwabe cycles and arguably identified a prolonged solar minimum in the late 17 th century 
Table 1. Summary of the names, intervals (onset and end), and references for known prolonged minima. Intervals have been adopted from Usoskin et al. (2007) for the three prolonged minima before 1610 and from Usoskin et al. (2015) for the Maunder Minimum. References have been abbreviated as YSTCC (the Yosemite Solar Terrestrial Coupling Conference in 1978), E76 (Eddy, 1976), SQ80 (Stuiver \& Quay, 1980), and SG80 (Stuiver \& Grootes, 1980).

\begin{tabular}{lcccc}
\hline Name & Onset & End & Origin & Reference \\
\hline Dalton Minimum & 1797 & 1827 & John Dalton & YSTCC \\
Maunder Minimum & 1645 & 1715 & Edward Maunder & E76 \\
Spörer Minimum & 1390 & 1550 & Gustav Spörer & E76 \\
Wolf Minimum & 1280 & 1350 & Rudolf Wolf & SQ80 \\
Oort Minimum & 1010 & 1050 & Oort & SG80 \\
\hline
\end{tabular}

Solar Cycles in 1610 - 2019

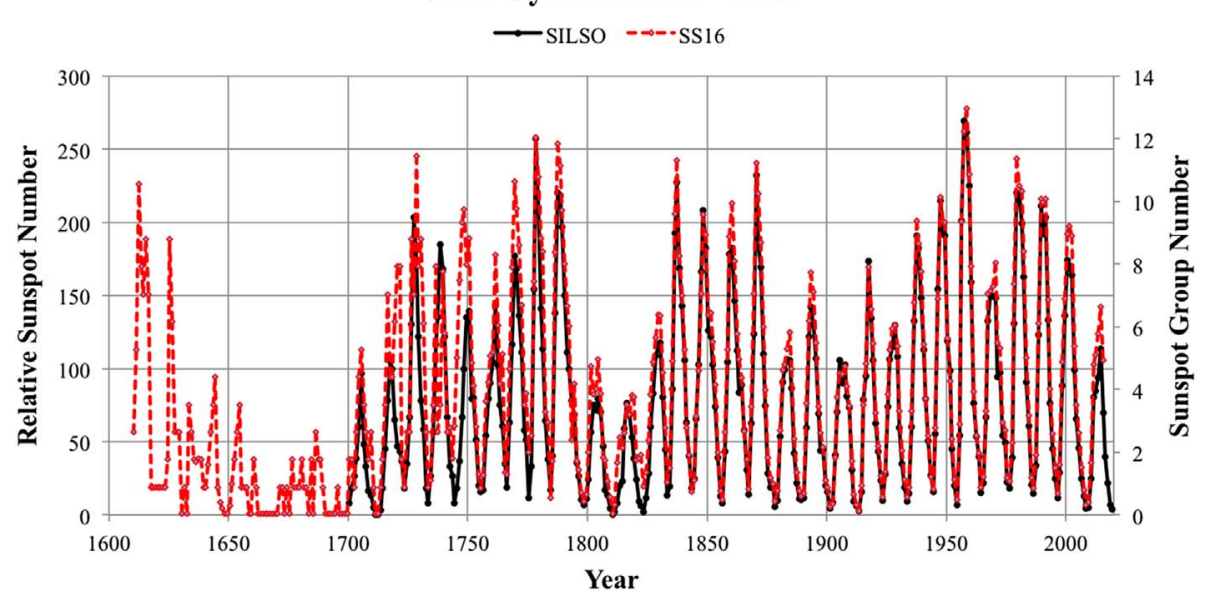

Fig. 1. Reconstructions of sunspot group numbers since 1610, visualized with relative sunspot numbers from SILSO (Clette \& Lefèvre, 2016; black continuous curve) and sunspot group numbers from Svalgaard \& Schatten (2016; red broken curve). Two prolonged minima are evident here: the Maunder Minimum (1645-1715) and Dalton Minimum (1797-1827). Note that the solar activity during the Maunder Minimum is considered much lower in other studies (e.g., Vaquero et al., 2015; Usoskin et al., 2015).

(Spörer, 1889), but gave its name to Edward Maunder (18511928). Another prolonged solar activity minimum occurred from 1280 to 1350 and was named the Wolf Minimum by Stuiver \& Quay (1980, pp. 16-18), after Rudolf Wolf (1816-1893), who established the principles for sunspot numbers and compiled the first comprehensive sunspot database (e.g., Clette et al., 2014; Friedli, 2016). A similar prolonged minimum occurred from 1010 to 1050 and was named the Oort Minimum by Stuiver \& Grootes (1980, pp. 170-71) after Jan Hendrik Oort (19001992), who contributed significantly to the fields of galactic studies and radio astronomy. These prolonged solar minima have been elaborately analyzed based on cosmogenic isotopes and are typically interpreted as grand minima in modern scientific studies (e.g., Usoskin et al., 2007; Inceoglu et al., 2015).

Similar prolonged solar minima have been identified in analyses of the long-term variability of cosmogenic isotopes. These earlier grand minima have been tentatively named as the Greek Minimum (390 to 330 BCE), Homeric Minimum (810 to 720 BCE), Egyptian Minimum (1410 to 1370 BCE), and Sumerian Minimum (3370 to 3300 BCE) based on cosmogenic isotope data (e.g., Fig. 7 in Landscheidt (1981)). However, these names have not been widely accepted in solar physics and are seldom used in modern scientific discussions.

At the Yosemite Solar Terrestrial Coupling Conference in 1978, John Eddy, George Siscoe and Sam Silverman (the co-author of the present paper), had an informal meeting to discuss these prolonged solar minima. In the course of this meeting the discussion came around to the various prolonged minima of the medieval period and later, focusing largely on the minimum which Eddy had named the Maunder Minimum, after the British astronomer who had written a seminal paper on the minimum from the middle of the 17 th century to the early years of the eighteenth century (e.g., Maunder, 1922). Silverman suggested to Eddy that it would be worthwhile to study the minimum around the beginning of the 19th century, since there are a greater number of scientific observers, more and better scientific instrumentation, and more scientific institutions involved in such studies, by contrast with the efforts of the previous centuries. Silverman suggested that Eddy do such a study. Eddy in turn suggested that Silverman do the study. In the course of this discussion the question of what to name this prolonged minimum. Silverman suggested that it be called the Dalton Minimum (see also Hayakawa et al., 2020b). His reasons were first, that Dalton had kept a meteorological diary for many years, that this diary included a long series of observations of auroras over many years, and that Dalton was the founder of atomic theory which had become the basis of all later work in what was then called natural philosophy. This suggestion was mutually accepted. Memory is fallible, Silverman here adds one set of facts in support: Eddy was an astronomer, Siscoe was a geophysicist, and Silverman's training and background was as a chemist ending up as a geophysicist, thus 
Silverman was the one most likely to be familiar with a man best known as a chemist.

However, using Dalton's names was a mutual decision by all three researchers and we believe that the attribution of the name should be given to all three. This is a prime example of how science should work as a collaborative effort. In the next section, we will provide examples of Dalton's work in meteorology and his studies of aurorae, which will demonstrate that he certainly deserves the distinction. The auroral records related to this minimum were subjected to detailed analyses and published by Feynman \& Silverman (1980), and Siscoe (1980), as reviewed by Eddy (1988) and Silverman (1992), who explicitly used the term of the Dalton Minimum to describe this solar minimum.

\section{Dalton and his studies}

Dalton's history is best summarized in a contribution he made to a book by a Mr. Roberts called the Book of Autographs in the form of a letter on 22 October 1832. He summarized his life as "Attended the village schools, there and in the neighbourhood, till eleven years of age, at which period he had gone through a course of mensuration, surveying, navigation, \&c.; began about twelve to teach the village school, and continued it two years; afterwards was occasionally employed in husbandry for a year or more; removed to Kendal at fifteen years of age as assistant in a boarding-school; remained in that capacity for three or four years, then undertook the same school as a principal, and continued it for eight years; whilst at Kendal, employed his leisure in studying Latin, Greek, French, and mathematics, with natural philosophy; removed thence to Manchester in 1793 as tutor in mathematics and natural philosophy in the New College; was six years in that engagement, and after was employed as private and public teacher of mathematics and chemistry in Manchester, but occasionally by invitation in London, Edinburgh, Glasgow, Birmingham, and Leeds." (Henry, 1854, p. 2).

Dalton was born in Eaglesfield, Cumberland on 6 September 1766 in the north of England (Smith, 1856; Millington, 1906, p. 5). He was educated at a village school until the age of 12 , and then immediately began teaching younger students (Millington, 1906, p. 7). He was self-taught thereafter with help from peers such as John Gough, a blind genius. He met Gough after he went to Kendal in 1781. It was at Gough's suggestion that he began to keep a meteorological journal in 1787, which he continued for $57 \mathrm{y}$, with the last entry being the day before his death in 1844 . His first entry into the journal was a description of an aurora. His meteorological observations at Kendal were published in 1793 (Dalton, 1793; second edition 1834). These will be discussed in greater detail below. Smith (1856, p. 10) estimated that Dalton made 40,000 meteorological observations, but also cited an estimate by a Mr. Harland of 200,000 observations (Smith, 1856, pp. 278-279). Dalton, having become distrustful of measurements from other individuals, constructed his own instruments, including a barometer, thermometer, and hygroscope (Millington, 1906, p. 12).

The variety of his interests during this period are indicative of his character, having a curiosity for every aspect of nature. Having his curiosity aroused, he would gather facts, either by observations or experiments, and then speculate on possible theories that would provide a description tying the facts together. As a simple example, in a letter to his friend William Alderson, he described the origins of English surnames (Millington, 1906, pp. 21-23). He collected botanical specimens and butterflies until 1793 (Smith, 1856, pp. 16-17), and also collected insects (Millington, 1906, p. 24). He and his brother offered a course of instruction by subscription. Next, in 1793, he moved to Manchester to teach at the New College. Finding the existing textbooks on grammar inadequate, he wrote his own book on the subject, which was published in 1801.

In Manchester, he became a member of the Manchester Society for Literature and Philosophy. His first paper in their journal, published in 1794, was an article on his color blindness. He subsequently became the Secretary of the Society and then President of the Society, as well as the editor for their journal. As the editor, he would sometimes write essays to fill space when there were insufficient contributions. Much of his original work was published there. Altogether, he published at least 116 papers in the journal (see the listing in Smith, 1856, pp. 253-261). Here, we mention a few of these papers to illustrate the variety of his interests: on the color of the sky: 1795, an essay on the mind: 1798 , a paper on grammar: 1800 , a paper on winds: 1832, on the specific heat of bodies: 1808, on meteorology: 1812, on the quantity of rain in the previous $25 \mathrm{y}$ : 1818, a paper on indigo: 1823, on $31 \mathrm{y}$ of meteorology in Manchester: 1825, two papers on the height of the aurora on 29 March 1826: 1826, and on an auroral arch on 3 November 1834: 1834. An interesting study in 1788 included "experiments on his own ingesta and egesta, in order to ascertain the weight lost by insensible perspiration: these were published, forty years afterwards, in the memoirs of the Manchester Society, vol. V, p. 303" (Henry, 1854, p. 14).

Dalton could often be acerbic in his comments. Commenting on a long paper presented at a meeting after being asked his opinion, he said "well, gentlemen, I daresay this paper is very interesting to those who take an interest in it" (Millington, 1906, p. 164). Smith (1856, p. 71) defined Dalton's character as follows: "he was a simple inquirer into nature, his enthusiasm rose only in her presence, his life was devoted to her study."

\section{Dalton's geophysical studies}

Dalton's early geophysical studies were conducted while he resided at Kendal. The corresponding observations and interpretations of results were published in 1793 (Dalton, 1793, 1834), shortly before his move to Manchester. A second edition was published in 1834, which consisted of a verbatim copy of the first edition with an appendix containing some observations on clouds, thunder, and meteors, with special focus on aurorae, including a listing of aurorae over the previous $40 \mathrm{y}$, which were additions to the first-edition listing of those he had observed in Kendal.

His motivation for this volume was to report on "... several things occurred to me which were new, at least to myself, and which throw light on the different branches of natural philosophy, and of meteorology in particular," in the form of essays "... in which are also given, such useful discoveries and observations of others as seemed necessary to be known, in order to form a proper idea of the present state of the science, and of the improvements that are yet to be made in it." These observations 


\section{Dalton's Auroral Observations}

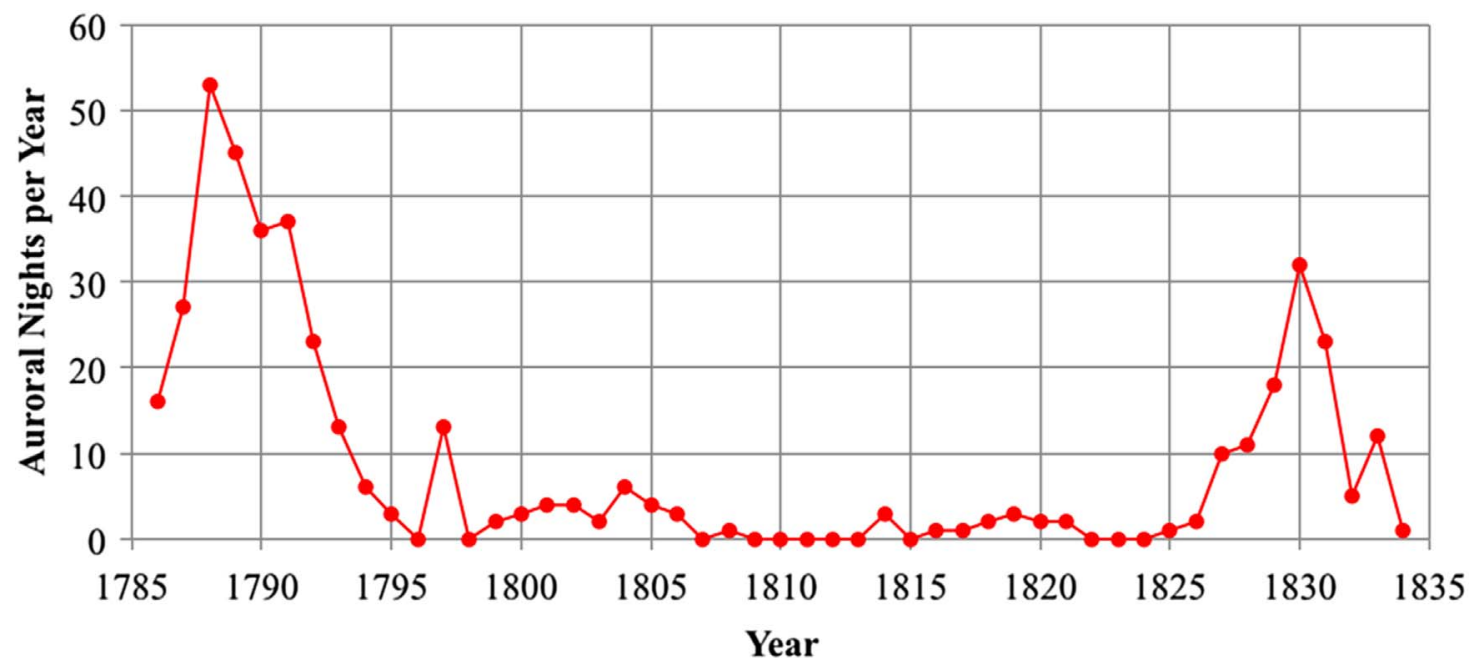

Fig. 2. Frequency of aurorae in Great Britain and Ireland according to Dalton's catalogs (1834). A prolonged minimum is clearly evident.

were made by Dalton at Kendal and by his friend Mr. Crosthwaite at Keswick. The observations of aurorae were new and, in some respects, original. As examples of work included in this volume, there was a second essay on the theory of trade winds, a third essay on variations in barometric pressure, and a seventh essay on the relationship between barometric pressure and rain. An eighth essay was published on the aurora borealis, including a discussion of Halley's work in the early 18th century and the use of a terrella to demonstrate the influence of magnetism on a spherical surface. An appendix used Dalton's barometrical observations to derive the heights of Kendal and Keswick above sea level, as well as the heights of mountains in the area around Keswick.

For the remainder of this paper, we will focus on Dalton's work on aurorae. Aurorae were a major interest of his and approximately one-third of the pages in the 1834 edition focused on aurorae.

\section{Dalton's catalog and descriptions of aurorae}

Dalton recorded a catalog of aurorae observed by himself at Kendal $\left(\mathrm{N} 54^{\circ} 20\right.$, W002 $2^{\circ}$ ) and by Crosthwaite at Keswick $\left(\mathrm{N} 54^{\circ} 36, \mathrm{~W}^{\circ} 03^{\circ} 09\right)$ from May of 1786 to May of 1793 (ibid. p. 54). In the second edition, he supplemented this list with a list of aurorae observed by himself at Manchester (N53 ${ }^{\circ} 29$, W002 ${ }^{\circ} 14$ ) and by others in England from 1793 to 1833 (ibid. p. $217 \mathrm{ff})$.

Among the detailed descriptions of aurorae, it is noteworthy that for the aurora on March 30,1793, the estimated height of the lower extremity of the beams was 62 English miles (ibid. p. 71). For the same aurora, Dalton noted that the auroral arches were all at right angles to the magnetic meridian (ibid. p. 70). He noted that the aurora on May 24, 1788 was "uncommonly brilliant" (ibid. p. 55). Regarding auroral influence on the magnetic needle, he noted that "I have never observed any con- siderable fluctuation of the needle in any evening but when there was an aurora visible" (ibid. p. 73).

In late 1834, Dalton noted that ". . . in fact, the light of the aurora exactly corresponds with that of the electric spark, when sent through a tube in which the air has been rarefied to as high a degree as can be effected by a good air-pump" (ibid. p. 244).

Observers of aurorae from the 18th century to the early part of the 20th century often reported a dark segment below the auroral arches. In a footnote, Dalton observed that (ibid. p. 233).

"This great black cloud which the author describes, was nothing more than the one which is usually seen (or rather imagined) under the low brilliant auroræ, and through which, stars of the first magnitude may be seen. It is a mere contrast of light and shade, and the cloud vanishes when the aurora does" (ibid. p. 233).

\section{Frequency of aurorae}

Dalton noted that aurora "has appeared frequently to all the northern parts of Europe since the year 1716, though it seems to have been a rare phenomenon before that time" (ibid. p. 53). This phenomenon is now recognized as the Maunder Minimum. He notes the scarcity of aurorae in the early 19th century, which is currently in his honor as the Dalton Minimum. He observed that there were no aurorae in $1798,1807,1809$ to 1813 , or 1822 to 1824 (ibid. p. 217). In a note, he added that in 1834, “ . . . the late period being one in which the phenomena were less common than they had been previously." He also noted that the aurorae were subject to long periods of intermission, stating (ibid. p. 227) "... the phenomena are subject to long periods of intermission. In some periods, they are rarely seen for great parts of an age; in other periods, they may be viewed 30, 40, or 50 times in each successive year, as was the case forty years since in Great Britain" (ibid. p. 227). Based on the auroral catalogs in Dalton's book (1834), Figure 2 clearly presents 


\section{Secular Variation of the MLATs at Kendal/Manchester}

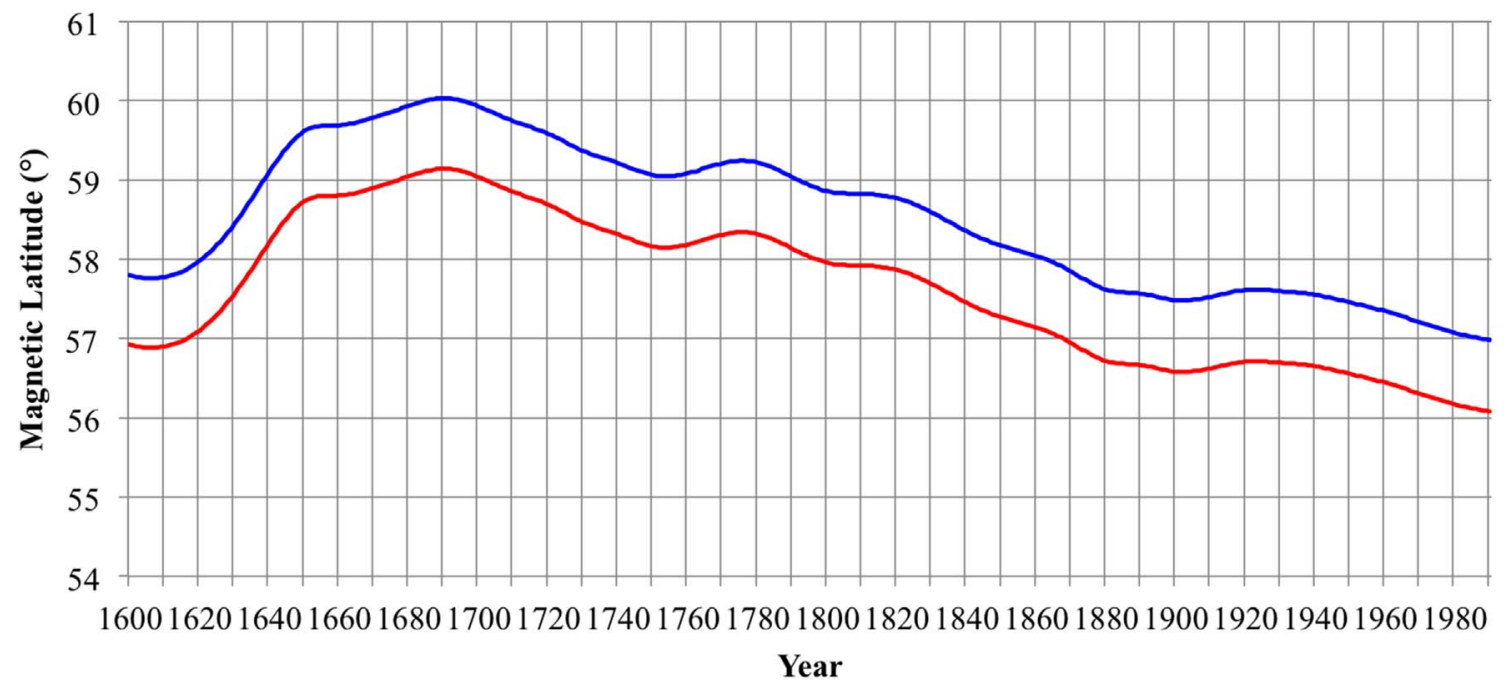

Fig. 3. Secular variation of MLATs at Kendal (blue) and Manchester (red) from 1600 to 1990.

the minimum auroral frequency at the end of the 18th and beginning of the 19th centuries.

As possible reasons for these variations and in consideration for the strong magnetic connection with aurorae, he suggested that "... a very plausible reason for the appearance of the aurora being so much more frequent now than formerly in these parts; if the earth's magnetic poles be like the centres of the aurora, as the phenomena indicate, it is plain the aurora must move along with them, and appear or disappear at places, according as the magnetic poles approach or recede from them; and hence it may be presumed that the earth's magnetic pole in the northern hemisphere is nearer the west of Europe in this century than it was in the last or preceding" (ibid. pp. 173-174).

\section{Annual variation of aurorae}

Dalton considered the possibility of lunar effects on aurorae, stating "... it occurred to him that the phenomena had more frequently happened about the change of the moon than at any other time; this produced the suspicion that the aerial tides occasioned by the moon might have some influence upon it." (ibid. p. 175). When comparing the spring and neap tides, he noted annual variation, including maxima in the Kendal auroral data in April, October, and November, and minima in July and December (ibid. p. 242). In the 1834 edition, he proposed an alternative cause, stating that the aurorae occurred most frequently "in those months when the transitions of temperature are most rapid" (ibid. p. 242). In any event, both explanations are likely to be connected to the orbital/solar relationships utilized in contemporaneous theories.

\section{Dalton's summary}

Dalton summarized his findings as follows: "The aurora consists of luminous arches or rings, drawn round the magnetic poles, in the manner of parallels of latitude around the poles of the earth on a terrestrial globe, and of luminous beams arising from them or amongst them, nearly perpendicular to the surface of the earth, or rather parallel to the dipping needle at the subjacent places. These concentric arches extend to $20^{\circ}$, sometimes $30^{\circ}$, but very rarely to $40^{\circ}$ from the magnetic poles: thus, the aurora is seldom seen to the south, in Iceland, which is about $25^{\circ}$ from the magnetic north pole; still more rarely in the Orkney and Shetland islands, which are $35^{\circ}$ from the pole; and very rarely over the middle of Great Britain and Ireland, which is nearly $40^{\circ}$ from the pole: thus, in the list recently given of 184 auroræ, only five or six arches were seen to pass the zenith, in this country . Auroræ are more numerous in the State of New York than in Britain, because that State is only $30^{\circ}$ from the magnetic pole" (ibid. pp. 240-241).

\section{Modern interpretations}

Dalton's implications are still valid and tell us volumes regarding the solar activity during/around the Dalton Minimum. Figure 3 presents the secular variation in the geomagnetic latitudes (MLATs) of Kendal and Manchester, where Dalton conducted his observations based on the GUFM1 model (Jackson et al., 2000). Their MLATs were approximately $2^{\circ}$ closer to the geomagnetic pole than those in 1990 and have progressed steadily toward the equator since then. Therefore, observers at Kendal and Manchester had a greater opportunity to see auroral displays in the past, as long as the solar activity remained at the same magnitude. However, as shown in Figure 2, the auroral frequency decreased significantly after the end of Solar Cycle 4 (April 1798; Table 2 in Hathaway, 2015) and remained extremely low until 1826 . The reported auroral frequencies still exhibit cyclic activity with apparent peaks at 1804 and 1814, slightly before the existing maxima of Solar Cycle 5 (February, 1805) and Solar Cycle 6 (May, 1816) in Table 1 in the paper by Hathaway (2015). 
Around the Dalton Minimum, the reported auroral frequencies peaked in 1788 and 1830, which agrees with the existing maxima of Solar Cycle 4 (February, 1788) and Solar Cycle 7 (November, 1829) in Table 1 in the paper by Hathaway (2015). Regarding the cycle amplitude, Solar Cycle 4 exhibited aurorae much more frequently than Solar Cycle 7. Although Dalton moved equatorward from Kendal to Manchester in 1793, this contrast is still striking and confirms the greater amplitude of Solar Cycle 4, which agrees with existing reconstructions of sunspot numbers (Clette \& Lefèvre, 2016) and a proxy-based heliospheric magnetic field (McCracken \& Beer, 2015). Additionally, Dalton's data show a local spike in 1797. This chronologically coincides with the lost cycle suggested by Usoskin et al. (2009), where sunspot positions may indicate another weak solar cycle at the end of Solar Cycle 4.

\section{Conclusions}

Dalton was a researcher of broad interest. Almost everything he observed required an explanation, whether it was botanical, meteorological, or chemical. His procedure was to first collect data. These were either his own observations, often using instruments of his own construction, or the published observations of others. These data were then classified and organized. Finally, he would search for a theoretical explanation for the observed data. As one might expect, his explanations relied on the knowledge available in his own time. Therefore, knowledge of the existence of the electron, which was discovered almost a century later, was not available to him. However, the questions he asked were still important.

Dalton's life straddled the prolonged solar minimum at the beginning of the 19th century. The breadth of his geophysical interests and his groundbreaking systemization of atomic theory easily justify the naming of this solar minimum after him.

Therefore, the Dalton Minimum was named after Dalton following discussions by John Eddy, George Siscoe, and Sam Silverman. Since this informal discussion, significant scientific progress has been achieved over the past few decades. The "Dalton Minimum" has become accepted in the solar community and has been analyzed in comparison to the Maunder Minimum (e.g., Clette et al., 2014; Usoskin, 2017). Analyses of contemporary records have shown sunspot numbers with distinct cyclicity, sunspot distributions in both solar hemispheres, and solar coronal streamers that are sufficiently bright for visual observations (Hayakawa et al., 2020a, 2020b). In contrast, the Maunder Minimum showed extreme suppression of solar cycles, southward concentration of sunspot distributions, and an apparent loss of coronal streamers (Eddy, 1976; Riley et al., 2015; Usoskin et al., 2015; Owens et al., 2017; Hayakawa et al., 2020c). However, there are a number of problems related to the current understanding of the Dalton Minimum, including the inconsistent reconstruction of solar cycles (e.g., Svalgaard \& Schatten, 2016; Muñoz-Jaramillo \& Vaquero, 2019), even when accounting for one solar cycle possibly lost in the early portion of the Dalton Minimum (Usoskin et al., 2009; Karoff et al., 2015; Owens et al., 2015). It is clear that these historical testimonies deserve further analysis. Because we have likely persisted through another small solar cycle, it may be worthwhile to reconsider Dalton's observations to understand how the sun behaves during a prolonged minimum.

Acknowledgements. We thank Rachel Rosenblum for her cordial support on our research activity. We appreciates financial supports of JSPS Grant-in-Aids JP20K22367, JP20K20918, and JP20H05643, JSPS Overseas Challenge Program for Young Researchers, the 2020 YLC collaborating research fund, and the research grants for the Mission Research on Sustainable Humanosphere from Research Institute for Sustainable Humanosphere (RISH) of Kyoto University and Young Leader Cultivation (YLC) program of Nagoya University. This work has been partly merited from participation to the International Space Science Institute (ISSI, Bern, Switzerland) via the International Team 417 "Recalibration of the Sunspot Number Series" and ISWAT-COSPAR S1-01 team.

\section{References}

Arlt R, Vaquero JM. 2020. Historical sunspot records. Living Rev Sol Phys 17: 1. https://doi.org/10.1007/s41116-020-0023-y.

Barnard L, McCracken KG, Owens MJ, Lockwood M. 2018. What can the annual ${ }^{10} \mathrm{Be}$ solar activity reconstructions tell us about historic space weather? J Space Weather Space Clim 8: A23. https://doi.org/10.1051/swsc/2018014.

Broughton P. 2002. Auroral records from Canada 1769-1821. J Geophys Res (Space Phys) 107(A8): 1152. https://doi.org/10.1029/ 2001JA000241.

Chatzistergos T, Usoskin IG, Kovaltsov GA, Krivova NA, Solanki SK. 2017. New reconstruction of the sunspot group numbers since 1739 using direct calibration and "backbone" methods. A\&A 602: A69. https://doi.org/10.1051/0004-6361/201630045.

Clette F, Lefèvre L. 2016. The new sunspot number: Assembling all corrections. Sol Phys 291: 2629-2651. https://doi.org/10.1007/ s11207-016-1014-y.

Clette F, Svalgaard L, Vaquero JM, Cliver EW. 2014. Revisiting the sunspot number. A 400-year perspective on the solar cycle. Space Sci Rev 186: 35-103. https://doi.org/10.1007/s11214-014-0074-2.

Daglis IA, Thorne RM, Baumjohann W, Orsini S. 1999. The terrestrial ring current: Origin, formation, and decay. Rev Geophys 37: 407-438. https://doi.org/10.1029/1999RG900009.

Dalton. 1793. Meteorological observations and essays. T. Ostell, London.

Dalton J. 1803. Meteorologische Beobachtungen. Ann Phys 15: 197-198.

Dalton J. 1834. Meteorological observations and essays, 2nd edn, Harrison and Crosfield, Manchester.

de Mairan JJD. 1733. Traite Physique et Historique de l'Aurore Boreale, Imprimerie Royale, Paris.

Domínguez-Castro F, Vaquero JM, Bertolin C, Gallego MC, De la Guía C, Camuffo D. 2016. Aurorae observed by Giuseppe Toaldo in Padua (1766-1797). J Space Weather Space Clim 6: A21. https://doi.org/10.1051/swsc/2016016.

Ebihara Y, Hayakawa H, Iwahashi K, Tamazawa H, Kawamura AD, Isobe H. 2017. Possible cause of extremely bright aurora witnessed in East Asia on 17 September 1770. Space Weather 15: 1373-1382. https://doi.org/10.1002/2017SW001693. 
Eddy J. 1976. The Maunder minimum. Science 192: 1189-1202.

Eddy JA. 1988. Variability of the present and ancient Sun: A test of solar uniformitarianism. In: Secular solar and geomagnetic variations in the last 10,000 years, Stephenson FR, Wolfendale AW (Eds.), NATO ASI Series, 236, Springer, Dordrecht, pp. 1-23. https://doi.org/10.1007/978-94-009-3011-7_1.

Feynman J, Silverman SM. 1980. Auroral changes during the eighteenth and nineteenth centuries and their implications for the solar wind and the long-term variation of sunspot activity. J Geophys Res 85: 2991-2997. https://doi.org/10.1029/JA085iA06p02991.

Friedli TK. 2016. Sunspot observations of Rudolf Wolf from 18491893. Sol Phys 291: 2505-2517. https://doi.org/10.1007/s11207016-0907-0.

Gonzalez WD, Joselyn JA, Kamide Y, Kroehl HW, Rostoker G, Tsurutani BT, Vasyliunas VM. 1994. What is a geomagnetic storm? J Geophys Res 99: 5771-5792. https://doi.org/10.1029/ 93JA02867.

Halley E. 1716. An Account of the late surprizing appearance of the lights seen in the air, on the sixth of March last; with an attempt to explain the Principal Phaenomena thereof. Philos Trans 29: 406-428.

Harrison G. 2005. Aurora diaries. Astron Geophys 46: 4.31-4.34. https://doi.org/10.1111/j.1468-4004.2005.46431.x.

Hathaway DH. 2015. The solar cycle. Living Rev Sol Phys 12: 4. https://doi.org/10.1007/lrsp-2015-4.

Hattori K, Hayakawa H, Ebihara Y. 2019. Occurrence of great magnetic storms on 6-8 March 1582. Mon Not R Astron Soc 487: 3550-3559. https://doi.org/10.1093/mnras/stz1401.

Hayakawa H, Mitsuma Y, Fujiwara Y, Kawamura AD, Kataoka R, Ebihara Y, Kosaka S, Iwahashi K, Tamazawa H, Isobe H. 2017a. The earliest drawings of datable auroras and a two-tail comet from the Syriac Chronicle of Zūqnīn. Publ Astron Soc Jpn 69: 17. https://doi.org/10.1093/pasj/psw128.

Hayakawa H, Tamazawa H, Uchiyama Y, Ebihara Y, Miyahara H, Kosaka S, Iwahashi K, Isobe H. 2017b. Historical auroras in the 990s: Evidence of great magnetic storms. Sol Phys 292: 12. https:// doi.org/10.1007/s11207-016-1039-2.

Hayakawa H, Mitsuma Y, Ebihara Y, Miyake F. 2019a. The earliest candidates of auroral observations in Assyrian astrological reports: Insights on solar activity around 660 BCE. Astrophys J Lett 884: L18. https://doi.org/10.3847/2041-8213/ab42e4.

Hayakawa H, Stephenson FR, Uchikawa Y, Ebihara Y, Scott CJ, Wild MN, Wilkinson J, Willis DM. 2019b. The celestial sign in the Anglo-Saxon chronicle in the 770s: Insights on contemporary solar activity. Sol Phys 294: 42. https://doi.org/10.1007/s11207019-1424-8.

Hayakawa H, Besser BP, Iju T, Arlt R, Uneme S, Imada S, Bourdin P-A, Kraml A. 2020a. Thaddäus Derfflinger's sunspot observations during 1802-1824: A primary reference to understand the Dalton Minimum. Astrophys J 890: 98. https://doi.org/10.3847/ 1538-4357/ab65c9.

Hayakawa H, Owens MJ, Lockwood M, Sôma M. 2020b. The solar corona during the total eclipse on 1806 June 16: Graphical evidence of the coronal structure during the Dalton minimum. Astrophys J 900: 114. https://doi.org/10.3847/1538-4357/ab9807.

Hayakawa H, Lockwood M, Owens MJ, Sôma M, Besser BP, van Driel L. 2020c. Graphical evidence for the solar coronal structure during the Maunder Minimum: Comparative study of the total eclipse drawings in 1706 and 1715. J Space Weather Space Clim. https://doi.org/10.1051/swsc/2020035.

Hayakawa H, Schlegel K, Besser BP, Ebihara Y. 2020d. Candidate auroral observations during the major solar-terrestrial storm in 1680: Implication for space weather events during the Maunder minimum. Astrophys J. https://doi.org/10.3847/1538-4357/ abb3c2.

Henry WC. 1854. Memoirs of the life and scientific research of John Dalton, Harrison and Sons, London. Printed for the Cavendish Society.

Inceoglu F, Simoniello R, Knudsen MF, Karoff C, Olsen J, TurckChiéze S, Jacobsen BH. 2015. Grand solar minima and maxima deduced from ${ }^{10} \mathrm{Be}$ and ${ }^{14} \mathrm{C}$ : magnetic dynamo configuration and polarity reversal. $A \& A$ 577: A20. https://doi.org/10.1051/0004$6361 / 201424212$.

Jackson A, Jonkers ART, Walker MR. 2000. Four centuries of geomagnetic secular variation from historical records. $R$ Soc Lond Philos Trans A 358: 957. https://doi.org/10.1098/rsta.2000.0569.

Karoff C, Inceoglu F, Knudsen MF, Olsen J, Fogtmann-Schulz A. 2015. The lost sunspot cycle: New support from ${ }^{10} \mathrm{Be}$ measurements. A\&A 575: A77. https://doi.org/10.1051/0004-6361/201424927.

Krivsky L, Pejml K. 1988. World list of polar aurorae $<55^{\circ}$ and their secular variations, Part II. Astron Inst Czech Acad Sci 75: 32-68.

Landscheidt T. 1981. Swinging sun, 79-year cycle, and climatic change. J Interdiscip Cycle Res 12: 3-19. https://doi.org/10.1080/ 09291018109359720.

Lockwood M, Barnard L. 2015. An arch in the UK Mike Lockwood, Luke Barnard. Astron Geophys 56: 4.25-4.30. https://doi.org/ 10.1093/astrogeo/atv132.

Lovering J. 1867. On the secular periodicity of the Aurora Borealis. Mem Am Acad Arts Sci 9: 101-111.

Maunder EW. 1922. The prolonged sunspot minimum, 1645-1715. J Br Astron Assoc 32: 140-145.

McCracken KG, Beer J. 2015. The annual cosmic-radiation intensities 1391-2014; the annual heliospheric magnetic field strengths 1391-1983, and identification of solar cosmic-ray events in the cosmogenic record 1800-1983. Sol Phys 290: 3051-3069. https://doi.org/10.1007/s11207-015-0777-x.

Millington JP. 1906. John Dalton, J.M. Dent \& Co, London.

Miyake F, Usoskin IG, Poluianov S. 2019. Extreme solar particle storms; the hostile Sun, IOP Publishing, Bristol, UK. https://doi. org/10.1088/2514-3433/ab404a.

Muñoz-Jaramillo A, Vaquero JM. 2019. Visualization of the challenges and limitations of the long-term sunspot number record. Nat Astron 3: 205-211. https://doi.org/10.1038/s41550018-0638-2.

Nevanlinna H. 1995. Auroral observations in Finland-Visual Sightings during the 18th and 19th centuries. J Geomagn Geoelect 47: 953-960. https://doi.org/10.5636/jgg.47.953.

Owens MJ, McCracken KG, Lockwood M, Barnard L. 2015. The heliospheric Hale cycle over the last 300 years and its implications for a "lost" late 18th century solar cycle. J Space Weather Space Clim 5: A30. https://doi.org/10.1051/swsc/2015032.

Owens MJ, Lockwood M, Riley P. 2017. Global solar wind variations over the last four centuries. Sci Rep 7: 41548. https:// doi.org/10.1038/srep41548.

Riley P, Lionello R, Linker JA, Cliver E, Balogh A, et al. 2015. Inferring the structure of the solar corona and inner heliosphere during the Maunder minimum using global thermodynamic magnetohydrodynamic simulations. Astrophys $J$ 802: 105. https://doi.org/10.1088/0004-637X/802/2/105.

Schröder W, Shefov N, Treder H. 2004. Estimation of past solar and upper atmosphere conditions from historical and modern auroral observations. Ann Geophys 22: 2273-2276. https://doi.org/ 10.5194/angeo-22-2273-2004.

Silverman SM. 1992. Secular variation of the aurora. Rev Geophys 30: $333-351$. 
Silverman SM. 1998. Early auroral observations. J Atmos Sol-Terr Phys 60: 997-1006. https://doi.org/10.1016/S1364-6826(98)00040-6.

Silverman SM. 2006. Low latitude auroras prior to 1200 C.E. and Ezekiel's vision. Adv Space Res 38: 200-208. https://doi.org/ 10.1016/j.asr.2005.03.158.

Siscoe GL. 1980. Evidence in the auroral record for secular solar variability. Rev Geophys 18: 647-658.

Smith RA. 1856. Memoir of John Dalton, M. Balliere, London.

Spörer G. 1889. Über die periodicität der Sonnenflecken seit dem Jahr 1618. Nova Acta der Ksl Leopold - Carol Dtschen Akademie der Naturforscher 53: 281-324.

Stephenson FR, Willis DM, Hallinan TJ. 2004. Aurorae: The earliest datable observation of the aurora borealis. Astron Geophys 45: 6.15-6.17. https://doi.org/10.1046/j.1468-4004.2003.45615.x.

Stephenson FR, Willis DM, Hayakawa H, Ebihara Y, Scott CJ, Wilkinson J, Wild MN. 2019. Do the Chinese astronomical records dated AD 776 January 12/13 describe an auroral display or a lunar halo? A critical re-examination. Sol Phys 294: 36. https:// doi.org/10.1007/s11207-019-1425-7.

Stuiver M, Grootes PM. 1980. Trees and the ancient record of heliomagnetic cosmic ray flux modulation. In: The ancient Sun: Fossil record in the earth, moon and meteorites; Proceedings of the Conference, Boulder, CO, October 16-19, 1979 (A81-48801 24-91), Pergamon Press, New York and Oxford, pp. 165-173.

Stuiver M, Quay PD. 1980. Changes in atmospheric carbon-14 attributed to a variable Sun. Science 207: 11-19. https://doi.org/ 10.1126/science.207.4426.11.

Svalgaard L, Schatten KH. 2016. Reconstruction of the sunspot group number: The backbone method. Sol Phys 291: 2653-2684. https://doi.org/10.1007/s11207-015-0815-8.

Usoskin IG. 2017. A history of solar activity over millennia. Living Rev Sol Phys 14: 3. https://doi.org/10.1007/s41116-017-0006-9.

Usoskin IG, Solanki SK, Kovaltsov GA. 2007. Grand minima and maxima of solar activity: New observational constraints. $A \& A \mathbf{4 7 1}$ : 301-309. https://doi.org/10.1051/0004-6361:20077704.

Usoskin IG, Mursula K, Arlt R, Kovaltsov GA. 2009. A solar cycle lost in 1793-1800: Early sunspot observations resolve the old mystery. Astrophys J Lett 700: L154-L157. https://doi.org/ 10.1088/0004-637X/700/2/L154.

Usoskin IG, Arlt R, Asvestari E, Hawkins E, Käpylä M, et al. 2015. The Maunder minimum (1645-1715) was indeed a grand minimum: A reassessment of multiple datasets. A\&A 581: A95. https://doi.org/10.1051/0004-6361/201526652.

Usoskin IG, Kovaltsov GA, Lockwood M, Mursula K, Owens M, Solanki SK. 2016. A new calibrated sunspot group series since 1749: Statistics of active day fractions. Sol Phys 291: 2685-2708. https://doi.org/10.1007/s11207-015-0838-1.

Vaquero JM, Vázquez M. 2009. The Sun recorded through history: Scientific data extracted from historical documents, Springer, Berlin. ISBN 978-0-387-92789-3.

Vaquero JM, Gallego MC, Barriendos M, Rama E, Sanchez-Lorenzo A. 2010. Francisco Salvá's auroral observations from Barcelona during 1780-1825. Adv Space Res 45: 1388-1392. https://doi.org/ 10.1016/j.asr.2010.02.009.

Vaquero JM, Kovaltsov GA, Usoskin IG, Carrasco VMS, Gallego MC. 2015. Level and length of cyclic solar activity during the Maunder minimum as deduced from the active-day statistics. $A \& A$ 577: A71. https://doi.org/10.1051/0004-6361/201525962.

Vázquez M, Vaquero JM, Gallego MC, Roca Cortés T, Pallé PL. 2016. Long-term trends and Gleissberg cycles in aurora borealis records (1600-2015). Sol Phys 291: 613-642. https://doi.org/ 10.1007/s11207-016-0849-6.

Willis DM, Davis CJ. 2015. Evidence for recurrent auroral activity in the twelfth and seventeenth centuries. In: New insights from recent studies in historical astronomy: Following in the footsteps, Springer International Publishing, Switzerland, p. 61. https://doi. org/10.1007/978-3-319-07614-0_6. ISBN 978-3-319-07613-3.

Willis DM, Stephenson FR. 2001. Solar and auroral evidence for an intense recurrent geomagnetic storm during December in $\mathrm{AD}$ 1128. Ann Geophys 19: 289-302. https://doi.org/10.5194/angeo19-289-2001.

Zanotti. 1738. Sopra l'aurora boreale comparsa il dì 16 dicembre, l'anno 1737, Pietro Bassaglia, Venezia.

Cite this article as: Silverman S \& Hayakawa H 2021. The Dalton Minimum and John Dalton's Auroral Observations. J. Space Weather Space Clim. 11, 17. https://doi.org/10.1051/swsc/2020082. 